\title{
Erratum to: Unique paleopathology \\ in a pre-Columbian mummy remnant from Southern Peru-severe cervical rotation trauma with subluxation of the axis as cause of death
}

Roman Sokiranski • Wolfgang Pirsig •

Hans-Peter Richter • Sandra Lösch • Ulrich Struck •

Andreas G. Nerlich

Published online: 9 November 2011

(C) Springer-Verlag 2011

\section{Erratum to: Acta Neurochir}

DOI 10.1007/s00701-010-0842-z

Two authors were missing:

S. Lösch and U. Struck

The correct order of authors should be: Roman Sokiranski, Wolfgang Pirsig, Hans-Peter Richter, Sandra Lösch, Ulrich Struck, Andreas G. Nerlich

The online version of the original article can be found at http://dx.doi. org/10.1007/s00701-010-0842-z.

R. Sokiranski $(\bowtie)$

Department of Radiology, University of Ulm,

Ulm, Germany

e-mail: sokiranski@gmx.net

W. Pirsig

Department of Otorhinolaryngology, University of Ulm,

Ulm, Germany

H.-P. Richter

Department of Neurosurgery, University of Ulm,

Ulm, Germany

A. G. Nerlich

Division of Paleopathology, Institute of Pathology,

Academic Teaching Hospital München-Bogenhausen,

Munich, Germany

S. Lösch

Department of Physical Anthropology, Institute of Forensic Medicine, Bern University,

Bern, Switzerland

U. Struck

Museum für Naturkunde Leibniz Institute for Research on

Evolution and Biodiversity, Humboldt University,

Berlin, Germany 